\title{
Rekonstruksi media interaktif berbasis kartun pada materi suhu dan kalor Kelas XI SMA
}

\author{
Violyta Ekka Caroline \\ Progam Studi Pendidikan Fisika, Universitas KH. A.Wahab Hasbullah, Indonesia \\ Surat-e: violyta2301@gmail.com \\ Ino Angga Putra \\ Progam Studi Pendidikan Fisika, Universitas KH. A.Wahab Hasbullah, Indonesia \\ Surat-e: inoanggaputra@unwaha.ac.id

\section{Suci Prihatiningtyas} \\ Progam Studi Pendidikan Fisika, Universitas KH. A.Wahab Hasbullah, Indonesia \\ Surat-e: suciningtyas@unwaha.ac.id
}

\begin{abstract}
Abstrak. Penelitian ini bertujuan untuk menghasilkan produk berupa media interaktif berbasis kartun, dan mengetahui kelayakan media interaktif berbasis kartun pada materi suhu dan kalor kelas XI SMA. Penelitian ini merupakan penelitian dan pengembangan yang menggunakan metode Borg and Gall. Hasil analisis data dari angket validasi ahli materi mendapat persentase $72,8 \%$ dengan kriteria valid, validasi ahli media mendapat persentase $81,6 \%$ dengan kriteria sangat valid, pendidik mendapat persentase $96,4 \%$ dengan kriteria sangat valid dan uji coba peserta didik mendapat persentase $92,3 \%$ dengan kriteria sangat valid. Hal ini menunjukkan bahwa media pengembangan valid atau layak untuk digunakan dalam pembelajaran materi suhu dan kalor kelas XI SMA. Harapan untuk media ini agar sumber belajar lebih bervariasi dan memberikan alternatif pemecahan masalah dalam pembelajaran fisika.
\end{abstract}

Kata kunci: media interaktif, kartun, suhu dan kalor

\begin{abstract}
The purpose of research to produce interactive media based on cartoons to know appropriate interactive media based on a cartoon on temperature and heat material on XI Grade Senior High School. The research design of this research is R \& D and the adapted Borg and Gall method. The result of analyzed data by a material expert is $72,8 \%$ score with valid criteria, by media expert is $81,6 \%$ score with very valid criteria, by teacher expert is $96,4 \%$ score with very valid criteria, by response questionnaire of students is $92,3 \%$ score with very valid criteria. It is known that media is valid or deserves to be able to learn on temperature and heat material XI Grade Senior High School. This research is R \& D. Hope for this media is so that learning resources are more varied and provide alternative problem-solving in learning physics.
\end{abstract}

Keywords: interactive media, cartoon, temperature dan heat

\section{Pendahuluan}

Perkembangan ilmu pengetahuan dan teknologi (IPTEK) mengalami perubahan disegala bidang, salah satunya dibidang pendidikan. Penerapan ilmu pengetahuan dan teknologi (IPTEK) dibidang pendidikan mengalami beberapa inovasi dalam pembelajarannya, salah satunya penggunaan media pembelajaran. Menurut Setyorini dkk (2016) media 
pembelajaran adalah alat untuk menyampaikan informasi sehingga proses pembelajaran dapat berlangsung secara efektif dan efisien [1]. Oleh karena itu media pembelajaran sangat penting dalam kegiatan pembelajaran.

Penggunaan media pembelajaran pada proses pembelajaran memiliki dampak yang baik untuk peserta didik. Hal ini didukung hasil penelitian Yulianti dimana media pembelajaran dapat mempermudah proses pembelajaran [2], dan meningkatkan variasi belajar [3]. Selain itu media pembelajaran membuat peserta didik mudah mengingat dan menyerap materi pembelajaran [4], serta dapat mengembangkan keterampilan proses sains [5]. Oleh karena itu, media pembelajaran dapat mendukung tercapainya tujuan pembelajaran secara efektif dan efisien.

Optimalisasi media pembelajaran di lapangan belum dilaksanakan secara maksimal. Hal ini dibuktikan dari hasil penelitian Sukanta bahwa media pembelajaran di lapangan belum dilaksanakan secara maksimal karena pendidik sering tidak menyiapkan media pembelajaran sehingga peserta didik kurang dalam penguasaan materi [6]. Akibatnya peserta didik belum mampu untuk menguasai materi. Kurang menariknya media pembelajaran juga menyebabkan peserta didik tidak tertarik terhadap materi yang disampaikan sehingga mempengaruhi pemahaman peserta didik terhadap materi tersebut [7]. Upaya mengatasi permasalahan tersebut digunakan media pembelajaran interaktif.

Media interaktif merupakan salah satu solusi untuk mengatasi permasalahan di lapangan. Media interaktif adalah media yang berupa audio, gambar, animasi, teks, video yang terdiri dari pembelajaran, peserta didik, dan proses pembelajaran [8]. Pernyataan ini menunjukkan bahwa peserta didik dapat bersemangat belajar dengan media interaktif karena tampilannya yang menarik dan mendukung pembelajaran menjadi lebih efektif dan efisien.

Media interaktif yang akan dikembangkan adalah media interaktif berbasis kartun. Kartun adalah gambar yang berpenampilan lucu dan menarik yang menggambarkan suatu peristiwa [9]. Kartun digunakan untuk menarik perhatian peserta didik sehingga peserta didik lebih mudah menyerap materi dalam pembelajaran.

Media interaktif kartun berpengaruh pada kegiatan pembelajaran. Hal ini didasarkan pada penelitian dari Sukanta bahwa dengan menggunakan media interaktif berbasis kartun dapat meningkatkan hasil belajar peserta didik [6]. Hal ini juga didukung penelitian dari bahwa dengan menggunakan media interaktif berbasis kartun peserta didik mampu belajar mandiri. Media interaktif berbasis kartun juga memberikan motivasi kepada peserta didik untuk memunculkan ide-ide, sehingga dapat memahami materi yang dijelaskan oleh pendidik [10].

Berdasarkan penjelasan di atas diharapkan dapat menghasilkan produk berupa media interaktif berbasis kartun dan mengetahui kelayakan media interaktif kartun pada materi suhu dan kalor kelas XI SMA. Media interaktif berbasis kartun ini juga dapat digunakan sebagai media pendukung peserta didik untuk bisa belajar mandiri. Oleh karena itu, penelitian yang akan dilakukan adalah rekonstruksi media interaktif berbasis kartun pada materi suhu dan kalor kelas XI SMA.

\section{Metode Penelitian}

Model penelitian yang digunakan adalah Research and Development (R\&D) atau penelitian pengembangan. Research and Development (R\&D) merupakan metode penelitian yang dilakukan untuk menghasilkan suatu produk tertentu, dan juga menguji keefektifan produk tersebut [11]. Pengembangan yang dilakukan menggunakan model prosedural dengan mengadaptasi model pengembangan Borg dan Gall. Prosedur penelitian dilakukan sampai pada tahap ketujuh yaitu revisi media tahap II. Adapun ketujuh tahapan tersebut ditampilkan pada gambar 1 berikut ini.

Analisis data pada penelitian ini adalah menggunakan teknik analisis deskriptif kualitatif dan kuantitatif. Deskriptif kualitatif adalah data yang diperoleh berupa masukan dari validator pada tahap validasi, juga masukan dari, ahli materi, pendidik, dan peserta didik. Sedangkan deskriptif kuantitatif adalah data yang memaparkan hasil pengembangan produk yang berupa media interaktif berbasis kartun. Data yang diperoleh melalui instrumen penilaian pada saat uji coba dianalisis dengan menggunakan statistik. Cara ini diharapkan dapat memahami data analisis. Hasil analisis data digunakan sebagai dasar untuk merevisi produk yang dikembangkan. Data berupa pendapat atau tanggapan pada uji produk yang dikumpulkan melalui angket kemudian dianalisis dengan statistik. Penelitian dilakukan di salah satu sekolah di Kabupaten Jombang Jawa Timur pada tanggal 21 Juli 2019. Kemudian data yang diperoleh juga dihitung dengan menggunakan persentase kelayakan media interaktif berbasis kartun. Adapun skala persentase dapat dilihat pada Tabel 1 .

Tabel 1. Skala Persentase [12]

\begin{tabular}{cc}
\hline Skor kelayakan & Kriteria \\
\hline \hline $81,0 \%-100,0 \%$ & Sangat layak layak digunakan \\
\hline $61,0 \%-80,0 \%$ & Layak layak digunakan \\
\hline $41,0 \%-60,0 \%$ & Cukup layak digunakan \\
\hline $21,0 \%-40,0 \%$ & Tidak layak digunakan \\
\hline $0,0 \%-20,0 \%$ & Sangat tidak layak digunakan \\
\hline
\end{tabular}




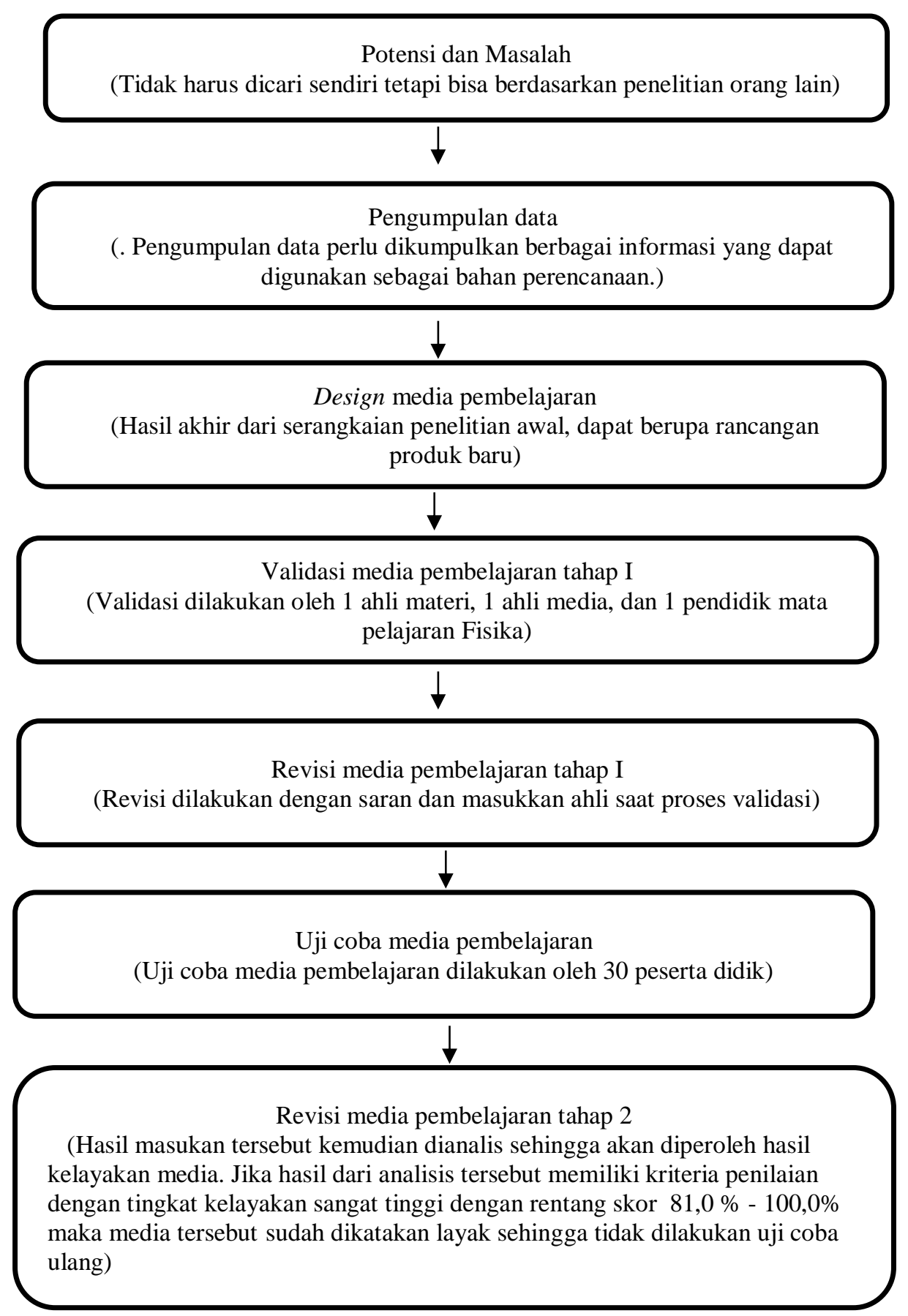

Gambar 1. Prosedur penelitian yang dilakukan

\section{Hasil Penelitian dan Pembahasan}

Hasil penyajian data uji coba media interaktif berbasis kartun materi suhu dan kalor didapat berdasarkan model penelitian yang digunakan adalah Research and Development (R\&D) atau penelitian pengembangan. Research and Development (R\&D) sebanyak 7 tahapan, sebagai berikut :

1. Potensi dan masalah. Potensi pengembangan media tersebut berguna untuk mengaktifkan pembelajaran di kelas pada pembelajaran Fisika, sehingga peserta didik lebih aktif dan tidak merasa bosan. Tahapan ini langsung dilakukan dengan wawancara yang berisi tentang sajian media pembelajaran karena peserta didik cenderung bosan dengan pembelajaran yang menggunakan media berupa buku (LKS);

2. Pengumpulan data, tahap ini dilakukan untuk memperoleh data awal tentang media interaktif dalam pembelajaran di kelas. Data awal tersebut digunakan sebagai bahan pada tahap selanjutnya yaitu tahap perencanaan; 
3. Desain media pembelajaran, tahap ini diawali dengan menyesuaikan standar kompetensi, kompetensi dasar dan indikator Fisika kelas XI SMA, selanjutnya media ini didesain dalam satu tampilan yang mencakup 6 menu yaitu menu kompetensi, menu baca aku, menu belajar, menu bermain, menu test, dan menu creator. Media ini telah dinilai kelayakannya oleh validator dan peserta didik bahwa media interaktif berbasis kartun ini termasuk dalam kriteria yang valid/layak digunakan dalam pembelajaran materi suhu dan kalor.

4. Validasi media pembelajaran. Tahap ini digunakan untuk dapat diketahui kelayakannya berdasarkan validasi ahli materi yang berkompeten di bidang pendidikan fisika, ahli media yang berkompeten dalam bidang media pembelajaran interaktif, dan pendidik mata pelajaran Fisika. Berdasarkan validasi, media interaktif berbasis kartun diperoleh hasil seperti terlihat pada tabel 2;

5. Revisi media pembelajaran tahap 1. Produk media yang sudah divalidasi selanjutnya direvisi sesuai dengan saran dan masukan ahli saat proses validasi;

6. Uji coba media pembelajaran. Setelah media pembelajaran interaktif berbasis kartun selesai direvisi kemudian dilakukan tahap uji coba media pembelajaran secara terbatas yang terdiri dari 30 peserta didik yang bertujuan untuk mengetahui respon peserta didik terhadap media pembelajaran interaktif berbasis kartun. Setelah menggunakan media, peserta didik mengisi angket untuk diminta kritik dan saran mengenai media pembelajaran interaktif berbasis kartun. Hasil uji coba peserta didik pada Tabel 3;

7. Revisi media pembelajaran tahap 2. Setelah dilakukan uji coba media pembelajaran akan diperoleh masukan dari peserta didik. Hasil masukan tersebut kemudian dianalis sehingga akan diperoleh hasil kelayakan media. Jika hasil dari analisis tersebut memiliki kriteria penilaian dengan tingkat kelayakan sangat tinggi dengan rentang skor 81,0\% - 100,0\% maka media tersebut sudah dikatakan layak sehingga tidak dilakukan uji coba ulang. Hasil ini menunjukkan bahwa media interaktif berbasis kartun valid/layak digunakan dalam pembelajaran materi suhu dan kalor. Hal ini juga didukung penelitian Sukanta, Ahmad, dan Aisyah tentang pengaruh media pembelajaran film kartun terhadap hasil belajar IPS terpadu (geografi) pada materi lingkungan hidup dan pelestariannya di kelas VIII SMP Negeri 1 Belitang III Kabupaten OKU Timur bahwa media pembelajaran sangat berpengaruh pada hasil belajar peserta didik [9]. Hasil penelitian dari Supriadi tentang penggunaan kartun matematika dalam pembelajaran matematika, juga menunjukkan bahwa media pembelajaran membuat pembelajaran menyenangkan, efektif, dan membuat peserta didik termotivasi untuk meningkatkan prestasi [12].

Berdasarkan hasil kajian produk yang didasarkan dengan landasan teori dan pemanfaatannya, dapat dinyatakan bahwa media interaktif berbasis kartun memiliki persamaan dengan penelitian sebelumnya yaitu a) Dapat menjadi media pendukung peserta didik untuk bisa belajar mandiri, b) Dapat digunakan kapanpun, c) Dapat membantu peserta didik bersemangat belajar karena tampilannya yang menarik dan mendukung pembelajaran menjadi lebih efektif dan efisien. Adapun perbedaan dari penelitian sebelumnya yaitu a) Media interaktif berbasis kartun ini dilengkapi cara penggunaan media agar pendidik dan peserta didik lebih mudah dalam menggunakan, b) Media interaktif berbasis kartun disertai dengan video praktikum agar peserta didik lebih memahami materi suhu dan kalor, c) media interaktif berbasis kartun disertai dengan simulasi (virtual lab) yang memudahkan peserta didik untuk belajar, d) Media interaktif berbasis kartun dapat memberikan umpan balik (feedback) berupa nilai kepada peserta didik setelah mengerjakan test. Gambar 2 sampai degan gambar 4 berikut ini adalah tangkapan layar dari media yang telah dikembangkan.



Gambar 2. Halaman Utama Media Interaktif Berbasis Kartun 


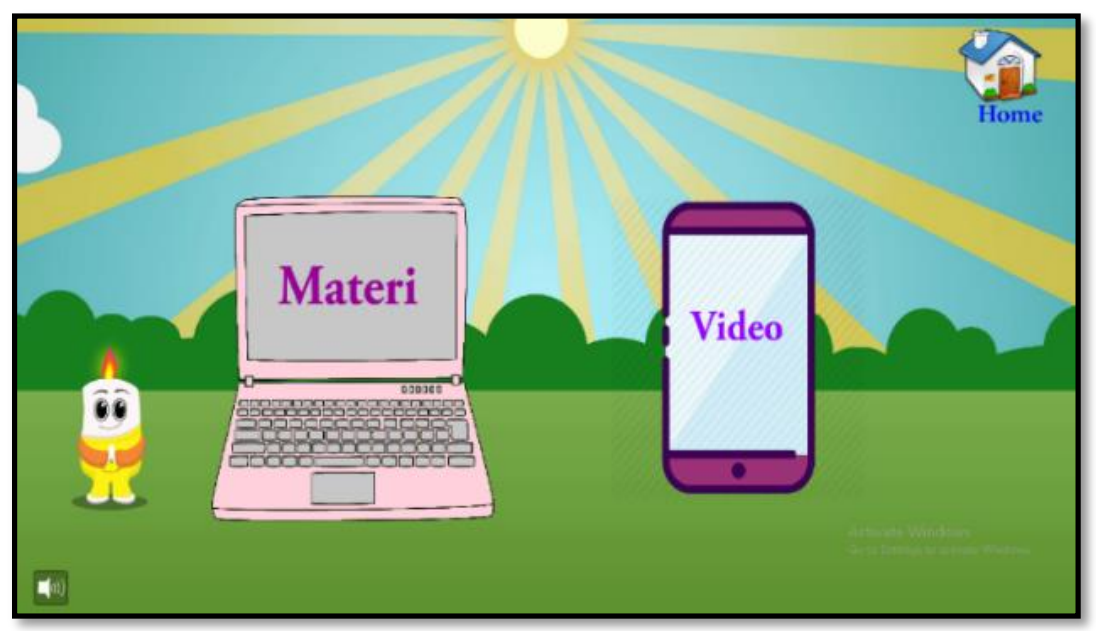

Gambar 3. Menu Belajar Media Interaktif Berbasis Kartun

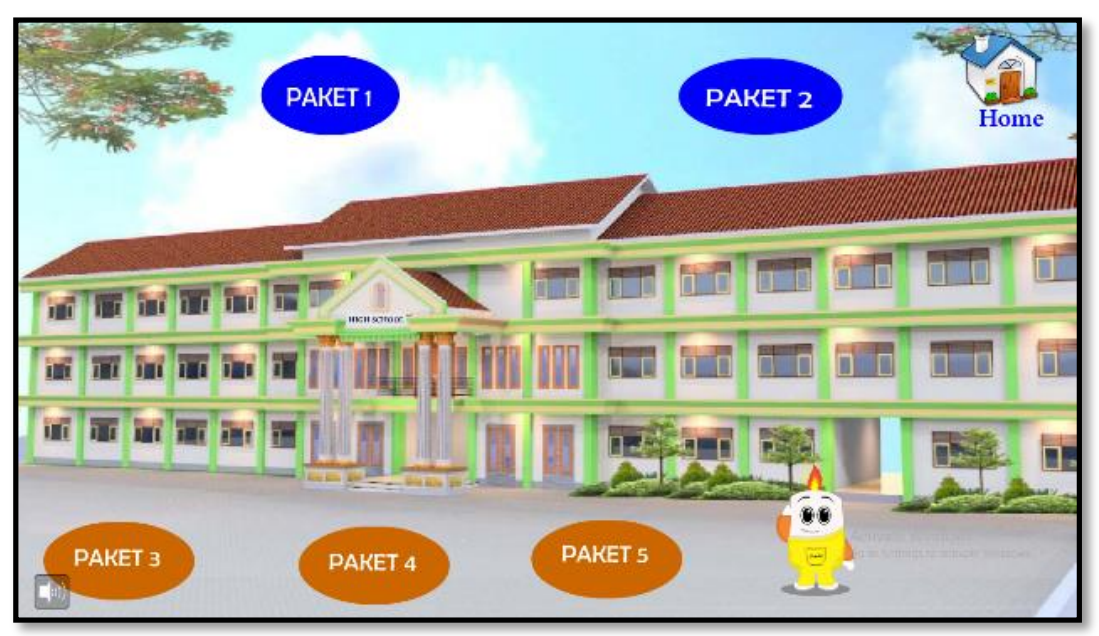

Gambar 4. Menu Test Media Interaktif Berbasis Kartun

Tabel 2. Skor hasil validasi

\begin{tabular}{ccc}
\hline Validasi & Skor & Kriteria \\
\hline Ahli materi & $72,8 \%$ & Baik \\
\hline Ahli media & $81,6 \%$ & Sangat baik \\
\hline Pendidik & $96,4 \%$ & Sangat baik \\
\hline
\end{tabular}

Tabel 3. Skor hasil uji coba terbatas

\begin{tabular}{ccc}
\hline Validasi & Skor & Kriteria \\
\hline Peserta didik & $72,8 \%$ & Baik \\
\hline
\end{tabular}

\section{Kesimpulan}

Penelitian dan pengembangan ini menghasilkan produk berupa media interaktif berbasis kartun, dan mengetahui kelayakan media interaktif berbasis kartun pada materi suhu dan kalor kelas XI SMA. Penelitian ini merupakan penelitian dan pengembangan yang menggunakan metode Borg and Gall. Hasil analisis data dari angket validasi ahli materi mendapat persentase 72,8\% dengan kriteria valid, validasi ahli media mendapat persentase $81,6 \%$ dengan kriteria sangat valid, pendidik mendapat persentase 96,4\% dengan kriteria sangat valid dan uji coba peserta didik mendapat persentase 92,3\% dengan kriteria sangat valid. Hal ini menunjukkan bahwa media pengembangan valid atau layak untuk digunakan dalam pembelajaran materi suhu dan kalor 
kelas XI SMA. Adapun saran pengembangan produk lebih lanjut adalah sebagai berikut adalah a) bagi semua pihak yang ingin mengembangkan media ini lebih lanjut, dapat dilakukan dengan cara menambahkan materimateri lain, sehingga produk yang dihasilkan lebih komprehensif, karena media ini hanya untuk materi suhu dan kalor; b) Contoh soal dan latihan soal perlu ditambahkan lebih bervariasi; c) Video praktikum dan virtual lab bisa ditambahkan; d) Perlu ditambahkan pembuatan proyek materi suhu dan kalor untuk melatih keterampilan peserta didik, e) Perlu adanya menu diskusi untuk membantu peserta didik mengembangkan pengetahuannya sendiri. Harapan untuk media ini agar sumber belajar lebih bervariasi dan memberikan alternatif pemecahan masalah dalam pembelajaran fisika.

\section{Kepustakaan}

[1] Setyorini, Patonah and Murniati, "Pengembangan Media Pembelajaran Moodle," Jurnal Penelitian Pembelajaran Fisika 7, vol. 7, no. 2, pp. 156-160, 2016.

[2] Y. F., Herkulana and Achmadi, "Pengaruh Penggunaan Media Pembelajaran terhadap hasil belajar siswa pada mata pelajaran ekonomi di SMA," Jurnal Pendidikan dan Pengajaran, vol. 4, no. 1, 2018.

[3] Sanaky, Media Pembelajaran Interaktif-Inovatif, Yogyakarta: Kaukaba Dipantara, 2013.

[4] P. Ekayani, "Pentingnya Penggunaan Media Pembelajaran untuk Meningkatkan Prestasi Belajar," in NiluhPutuYani.Artikel, 2017.

[5] I. Putra and E. Sujarwanto, "Analisis Keterampilan Proses Sains Peserta Didik melalui bahan ajar Multimedia Interaktif Alat Ukur dan Pengukuran dengan Pendekatan Behavioristik," Momentum : Physics Education Journal, vol. 1, no. 2, pp. 91-102, 2017.

[6] Sukanta, Ahmad and Aisyah, "Pengaruh Media Pembelajaran Film Kartun terhadap terhadap hasil belajar IPS Terpadu (Geografi) pada Materi Lingkungan Hidup dan Pelestariannya di kelas VIII SMP Negeri 1 Belitang III Kabupaten OKU Timur Tahun Pelajaran 2016/2017," Jurnal Swarnabhumi, vol. 2, no. 1, 2016.

[7] C. D. L., Saputro and Catur, " Pengembangan Multimedia Interaktif dengan Menggunakan Progam Adobe Flash untuk pembelajaran Kimia Materi Hidrolisis Garam Kelas XI," Jurnal Pendidikan Kimia, vol. 4, no. 2, 2015.

[8] T. W. and Siagian, "Pengembangan Media Pembelajaran Interaktif pada Pembelajaran Ekonomi," Jurnal Teknologi Informasi \& Komunikasi dalam Pendidikan, vol. 2, no. 2, 2015.

[9] Sukanta, Ahmad and Aisyah, "Pengaruh Media Pembelajaran Film Kartun terhadap terhadap hasil belajar IPS Terpadu (Geografi) pada Materi Lingkungan Hidup dan Pelestariannya di kelas VIII SMP Negeri 1 Belitang III Kabupaten OKU Timur Tahun Pelajaran 2016/2017," Jurnal Swarnabhumi, vol. 2, no. 1, 2016.

[10] S. Atun, "Media Development of Science Cartoon in Subject of Magnetic Force for Fifth Grade Class of SD Negeri 1 SekarSuli," in Jurnal Pendidikan Guru Sekolah Dasar Edisi 1, 2016.

[11] Sugiono, Buku Metode Penelitian Kuantitatif, Kualitatif dan R\&D, Bandung: Alfabeta, 2012.

[12] Supriadi, "Penggunaan Kartun Matematika dalam Pembelajaran Matematika," Jurnal Pendidikan Dasar, vol. 10, 2008. 